\title{
Channel bed processes experimental modeling in the area of damless water intake
}

\author{
Bekhzod Norkulov ${ }^{1}$, Gulnora Jumabaeva ${ }^{1}$, Farokhiddin Uljaev ${ }^{1}$, Farkhod Jamalov ${ }^{2}$, Anvar \\ Shomurodov $^{2}$, and Azizali Qurbanov ${ }^{1}$ \\ ${ }^{1}$ Tashkent institute of irrigation and agricultural mechanization engineers, Tashkent, Uzbekistan \\ ${ }^{2}$ Bukhara Branch of the Tashkent Institute of Irrigation and Agricultural Mechanization Engineers, \\ Bukhara, Uzbekistan
}

\begin{abstract}
The article presents the main results of substantiating the materials used when conducting experimental studies of channel processes in a river, the channel of which is composed of easily eroded soils. It is substantiated that the Amudarya sand cannot be modeled on a geometric scale since the model deposits are too small (powder) and lose the property of loose bodies. In such cases, a material with a decrease in specific gravity without a decrease in diameter is used as a substitute for sand. Since the sediment diameter cannot be reduced, the actual scale of the model remains distorted. It is indicated that the sediment diameter cannot be reduced, then in fact, the scale of the model remains distorted. Therefore, when the bottom of a river bank is made of sand that does not lend itself to geometric modeling, regardless of the change in the specific gravity of the natural material, to ensure the mobility of the sand on the model, it is necessary to distort the vertical scale.

Distortion of scales is also necessary because when using in laboratory conditions the same sand that formed the bed of the river, at any depth with a low velocity, the model observes bottom resistances to the flow of the flow compared with nature. The vertical and plan scales of modeling were calculated, respectively, equal to 50 and 57. According to the results of the calculations, the value of the coefficient of mobility of bottom sediments was established, which was equal to 1 .
\end{abstract}

\section{Introduction}

Water intake from the river in a damless way is widely used in the middle reaches of the Amu Darya. Even though this method of water withdrawal is cheaper than the dam method, it requires a lot of capital expenditures to ensure reliable operation. At the same time, many problems arise in the operation of the head structure. The solution to any production problem with damless water intake is an urgent task for channel hydraulics. Proceeding from the foregoing, the object of study is the section of the Amu Darya River, where the damless water intake to the Amu Bukhara Main Canal (ABMC) is carried out.

At present, water intake at $\mathrm{ABMC}$ is carried out through the reconstructed head structure, located $26 \mathrm{~km}$ above the Chardzhou railway bridge and is located $14 \mathrm{~km}$ upstream of the river from the water intake point. The channel of the Amu Darya river in 
this section is strongly deformed and divided into branches, in which a significant change in water discharge can occur within a short time. With a damless water intake, more than $20 \%$ of difficulties occur during the non-growing season. Under these conditions, a dam or spur water intake is required. It turned out to be expedient to construct a new head structure (slightly above the entrance to the existing slot) with a stream-guide dam in the channel of shell piles, ensuring a constant flow of the flow in one channel at the water intake.

In the conditions of the Amu Darya, the elaboration of regulating and straightening structures by calculation and forecasting channel processes without special studies is a difficult and almost insoluble task [1-4]. Therefore, studying and developing the theory of channel processes, the dynamics of channel flows has always attracted the attention of scientists [5-] The interaction of the stream and channel determines the main dynamic essence of the channel process. The introduction to the scientific literature of the concept of "channel process" was initiated by the representatives of classical channel hydraulics $[5,6]$ according to which "channel process is the process of interaction between the stream and channel" or [6] in the channel process "the river bottom relief is developed in the process of interaction of the flow and the underlying soils ", that is, the stream and the soil interact, having a common contact surface - the bottom of the river and the floodplain [7].

In [8], based on many years of research, they somewhat expanded the concept of the channel process and concluded that "the channel process is understood as a constant change in the morphological structure of a river that occurs under the influence of flowing water».

So, studying the above works and relying on the results of field studies, we can conclude that the flow interacts with the soil along which the water moves, and the channel appears as a result of this interaction.

A large number of works are devoted to studying the development of the theory of channel processes and the dynamics of channel flows.

According to many authors of the above works, the channel process is due to the following set of main factors:

- hydrological, which are determined by the water regime of the river;

- geomorphological, which are determined by the geology and structure of the channel and banks;

- sediment runoff from the river basin and their granulometric composition;

- the influence of human economic activity.

Recently, the study of channel processes has been developing in two main directions, depending on the task set for the researchers.

The first direction is engineering-hydrological, which mainly studies the laws of the formation of river channels and their elements and the mechanism of the phenomena that make up the channel process.

The second direction is geological and geomorphological. The processes of formation of river valleys and the development of the river network are studied, and its main method is the morphological analysis of channel processes.

Researchers, studying the vast material of field studies, developed a hydro morphological method of analysis that combined the methods used in geomorphology, hydrology, and hydrodynamics. It was named hydro morphological. This hydro morphological direction has played an important role in understanding the essence of channel processes. An especially important role was played by the theory of hydro morphometric relationships of dynamically stable channels [9-13].

The results of extensive theoretical and laboratory studies presented in these works made it possible to reveal the most important qualitative and quantitative aspects of the phenomenon.

Despite the abundance of works devoted to this problem, its solution is still far from practical completion. The reason for this is the complexity and multifactorial nature of the 
course of channel processes in space and time. Especially great difficulties arise in the design of head structures with a damless water intake from the Amu Darya, the channel of which, due to the large slopes of the bottom, high flow rates and easy erosion of bottom sediments (represented by fine sandy weak soils), is subject to extremely complex intense planned and deep deformations [6-8]. To solve this problem, it is recommended to use physical - experimental modeling, which can give a specific forecast of channel deformations in the area of the damless water intake to the head structure. It should be noted that although experimental modeling requires a lot of material costs and a lot of research time, it is quite acceptable to numerical research [1]. Therefore, it is necessary to carry out experimental studies of the structures and the adjacent section of the river bed where the damless water intake is carried out at the ABMC. Accordingly, the implementation of experimental studies of structures and the adjacent section of the river channel where the damless water intake is carried out at the ABMC is defined as the main goal of this work.

To achieve this goal, the following research objectives have been identified:

1) Justification for the use of experimental research material;

2) Determination of the vertical and planned scales of modeling of channel processes;

3) determination of the maximum possible water intake from the river into the canal through the head regulator at different flow rates in the river;

4) establishing the value of the coefficient of sediment mobility.

\section{Methods}

The degree of correctness of the planned measures and their impact on the flow is determined mainly by the similarity of channel processes in everyday conditions and on the model. Therefore, before solving the main issues, it is necessary to clarify the modeling technique. Considerations of the basic conditions of modeling and, as a result, determine the modeling method is the research methodology of this work.

Studying channel processes in the laboratory through experimental research, it is possible to obtain qualitative and quantitative similarity between nature and model, which is determined by the similarity of flow hydraulics and channel shape, subject to the condition of sediment mobility. Modeling channel processes and the hydraulic structure of the flow in lowland rivers in compliance with geometric similarity has always yielded satisfactory results, which are in good agreement with nature. To ensure the similarity of the occurring phenomena of the model with nature, the researchers modeled the depth on a larger scale compared to the width, i.e. distorted the scale of the model.

\section{Results and Discussion}

The admissibility of the distortion of the scales can be explained by the fact that the ratio of the flow depth to its width H/B under the conditions of the Amu Darya river for large water flows is much less than for small ones. Consequently, a small flow creates relatively large depths $(\mathrm{H} / \mathrm{B})$, as if distorting its vertical scale. This means that the morphometric relationship in the form of $\frac{\sqrt{B}}{H}$ cannot remain constant, but it can change. On channel models, the following are used as sediments: natural sand, steam locomotive ash, calcined sawdust, etc.

The Amudarya sand cannot be modeled on a geometric scale since the model deposits are too small (powder) and lose the property of loose bodies. In such cases, a material with a decrease in specific gravity without a decrease in diameter is used as a substitute for sand. 
Since the sediment diameter cannot be reduced, the actual scale of the model remains distorted. Therefore, when the bottom of a river bank is made of sand that does not lend itself to geometric modeling, regardless of the change in the specific gravity of the natural material, to ensure the mobility of the sand on the model, it is necessary to distort the vertical scale.

Distortion of scales is also necessary because when using in laboratory conditions the same sand that is used to form the bed of the river, at any depth with a low velocity, the model observes bottom resistances to the movement of the flow in comparison with nature. So, according to the studies of many experimenters [13], the nature of the movement and the shape of the riffles (ridges) depends on the relative critical velocity $\frac{U}{U_{0}}$ and turbidity. At $\frac{U}{U_{0}}=2$, attraction to the bottom occurs, at $\frac{U}{U_{0}}=3$, the ridge collapses and the bottom is smoothed out, and at $\frac{U}{U_{0}} \geq 5$, the ridge disappears and the sediments move simultaneously at the bottom and in the body of the stream, i.e. part of the sediment passes into suspension. On the model, it is impossible to increase the $\frac{U}{U_{0}}$ ratio to significant values (as in nature). But by changing the supply of sediment discharge, it is possible to set the depth and flow rates on the model corresponding to the accepted Froude number according to natural data, even under the condition $\left(\frac{U}{U_{\text {омод }}}\right)<\left(\frac{U}{U_{\text {онат }}}\right)$. Modeling in terms of the Froude number and resistance should ensure the mobility of the model material, i.e. the condition must be met $\frac{U}{U_{0}}>1[7,14]$. The essence of the above requires that the value of the dimensionless index of kinetic $F_{r}=\frac{u^{2}}{g h}$ with the obligatory observance of the similarity of the form, to obtain the scale of the water discharge $\alpha_{q}=\alpha_{B} \cdot \alpha_{h}^{1.5}$. It is also obtained from the condition of similarity of the resistance of the channel bottom according to the equation of the uniform steady-state flow regime, i.e. from $Q=B H \frac{1}{n} H \sqrt{H J}$ whence we obtain

$$
\alpha_{q}=\alpha_{B} \cdot \alpha_{h}^{1.5+\mathrm{y}} \cdot \alpha_{i}^{0.5}
$$

From the equality of the scale of expenditures in terms of the Froude number and the equation of uniform motion, we obtain:

$$
\alpha_{B} \alpha_{h}^{1,5}=\frac{\alpha_{B} \alpha_{h}^{1,5+\mathrm{y}} \alpha_{i}^{0,5}}{\alpha_{n}}
$$

from here:

$$
\alpha_{n}=\alpha_{B} \cdot \alpha_{h}^{\mathrm{y}} \cdot \alpha_{i}^{0.5}
$$

As you can see, the last equality has two unknowns for a given value. Therefore, the direct use of the value of the scale of depth and slopes to determine the scale of the roughness coefficient is impossible without preliminary methodological studies. Roughness is usually determined by the particle diameter and the shape of the movement of the sand deposits. Since bottom riffles (ridge) can be observed in the model channel, it is quite natural that the depth scale will be distorted. In Uzbekistan, some modeling techniques have been developed for the conditions of the Amu Darya River. One of the most widespread methods of approximate modeling of eroded channels is the method given in [15]. It is based on the use of the morphometric dependence $B^{m}=k H$, from which the ratio of the horizontal and vertical scales of the model was obtained 


$$
\alpha_{h}=\alpha_{B}^{m}
$$

where: $m$ is a variable exponent determined by the dependence $m=0.72\left[\frac{d(\sigma-1)}{H J}\right]^{0,1}$.

For the conditions of the Amu Darya, the exponent " $\mathrm{m}$ " is taken equal to 0.65.

$\alpha_{B}$ and $\alpha_{h}$ are respectively, the plan and vertical scales of the model.

With a numerical value $\alpha_{B}=500$, which is taken from the condition of the size of the model area, the vertical scale will be:

$$
\alpha_{h}=\alpha_{B}^{0.57}=500^{0.65}=57
$$

It is proposed to determine the vertical scale from the condition of mobility of the material used on the model by the formula

$$
\alpha_{h}=\sqrt{\alpha_{B} \alpha_{d} \alpha(\sigma-1)}
$$

Sand with an average diameter of $\mathrm{d}=0.34 \mathrm{~mm}$ was used as bottom sediment. With a specific gravity of $2.7 \mathrm{t} / \mathrm{m}^{3}$, the sediment mobility coefficient is determined by the formula

$$
\alpha_{(\sigma-1)}=\frac{(\sigma-1)_{H}}{(\sigma-1)_{M}}=\frac{2.7-1}{2.7-1}=1
$$

According to the data of borehole samples, the average diameter of the Amu Darya sediments in the area of the water intake of the Amu-Bukhara canal is taken as $0.3 \mathrm{~mm}$. Then the sediment size factor is

$$
\alpha_{d}=\frac{\alpha_{H}}{\alpha_{M}}=\frac{0.3}{0.34}=0.882
$$

Vertical scale, taking into account the mobility of the material taken on the model for the planned scale $\alpha_{B}=500$, will be

$$
\alpha_{B}=\sqrt{500 \cdot 1 \cdot 0.882}=21
$$

As can be seen, the scale factor of the depth obtained from the condition of the similarity of the Froude number and the drag coefficient and the mobility of sediments and morphometric connection are different. The value of the vertical scale, taking into account the mobility, gives a significantly higher water flow rate on the model, making it difficult to conduct experiments. On the other hand, it is unknown how the Froude number and the drag coefficient will change. The vertical scale is related to the flow rate of sediment supplied to the flow in the model. Thus, the refinement of the value of the vertical scale (for a given value of the length scale) consisted of determining the sediment discharge, which ensures the similarity of the Froude number in certain values of the drag coefficient on the model.

For the Amu Darya river, the water discharge in the model can vary depending on the vertical scale within a wide range. However, the change in the velocity of the flow depth and the Froude number will be unknown. Therefore, in each case, it is necessary to conduct methodological experiments, taking into account the availability of material, the size of the laboratory area, and the pumping unit's capacity.

To find the optimal ratio of scales, we carried out experiments, the practical meaning of which was to find such velocities and depths of the flow at which the mobility of sediments, as well as the similarity of the shape of the channel in the profile and in the plan. 
In methodological experiments, the values of the channel width on the model were taken following the flow rates in kind according to the schedule $Q=f(B)$ figure 1 .
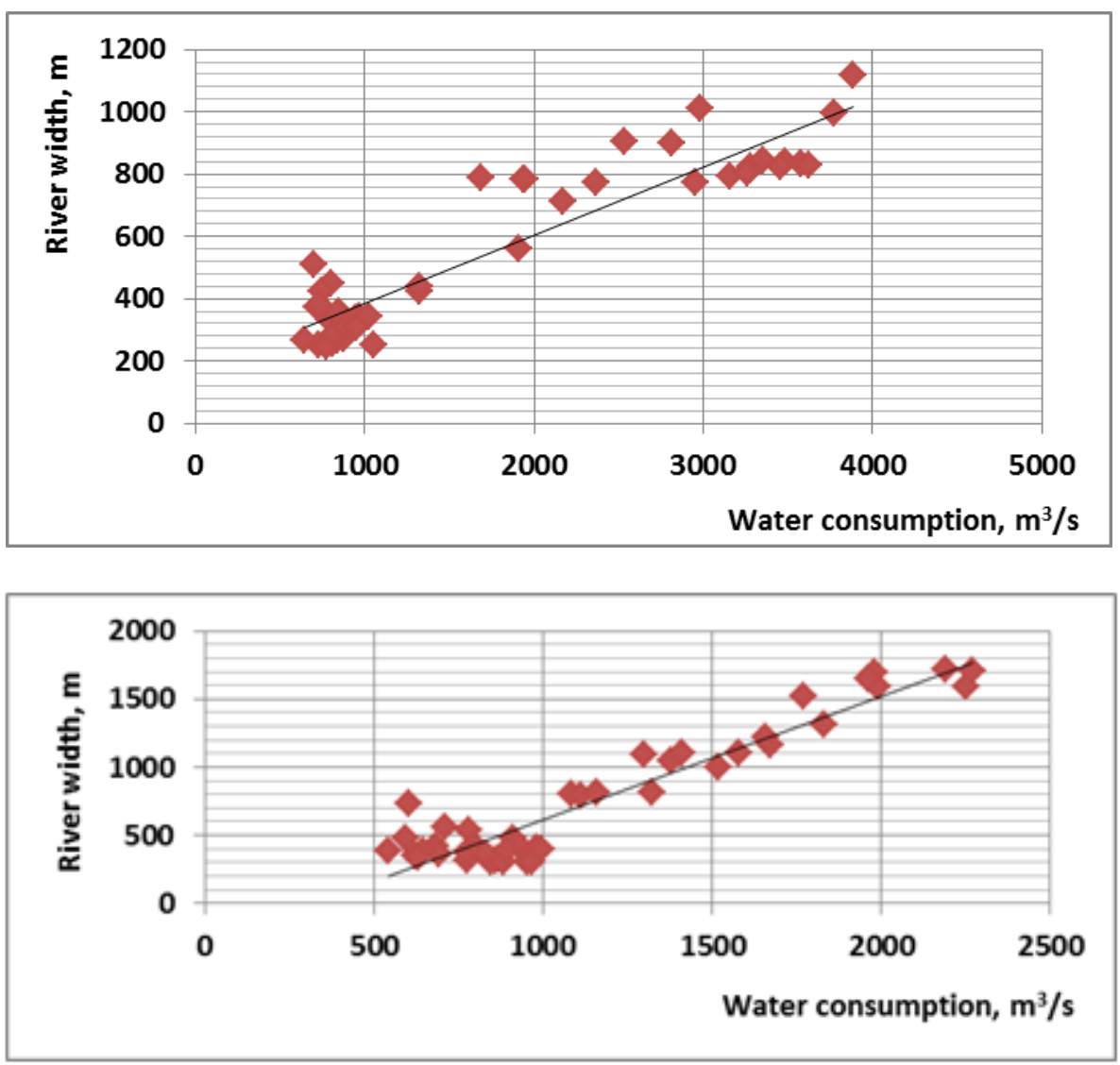

Fig. 1. Diagram of the relationship between the channel width and the water discharge in the Amu Darya river bed in the area of the damless water intake at the ABMC.

Assuming the width of the channel for a given water flow rate on the model is constant, and the flow was supplied with different sediment flow rates.

In each experiment, after obtaining the balance of sediments and establishing the horizons in the designated two sections, the average depth, velocity, and cross-sectional area of the channel were measured. As you know, hydraulic flow elements in nature are also associated with water consumption. 


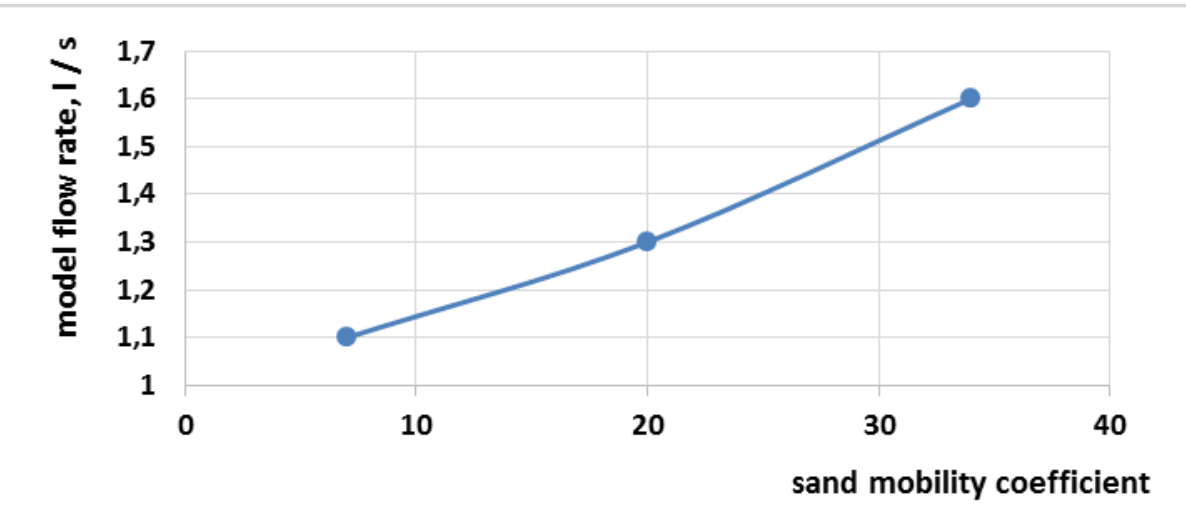

Fig. 2. Graph of the relationship between the value of model flow rates and the coefficient of mobility of sand

As a result, the optimal value of the vertical scale meets all the requirements of the principle of modeling the eroded river bed at a given scale of width $\alpha_{B}=500$ n.v. installed $\alpha_{h}=40$

Since the exact reproduction of deformable channels is impossible, the method of approximate modeling was used to solve the set tasks, i.e. by average hydraulic flow elements.

To obtain reliable data on the channel processes occurring along the dam on the model, the diameter of the shell piles must be modeled so that the flow regime of the shell piles in nature is preserved on the model. A significant decrease in the structure entails a corresponding decrease in the flow rate, as a result of which a laminar flow regime, together with turbulent in nature, can occur on the model at the through spur. The optimal diameter of the shell piles of the jet-directing through the dam on the model is determined based on the condition under which the flow runs perpendicularly and uniformly along the entire front of the through dam. Then the constraint coefficient can be taken $K_{0}=1$, as the maximum possible interrupted flow. The angle of installation of the spur (dam), taking into account the curvature in the plan, on average, is taken $\theta=30^{\circ}$.
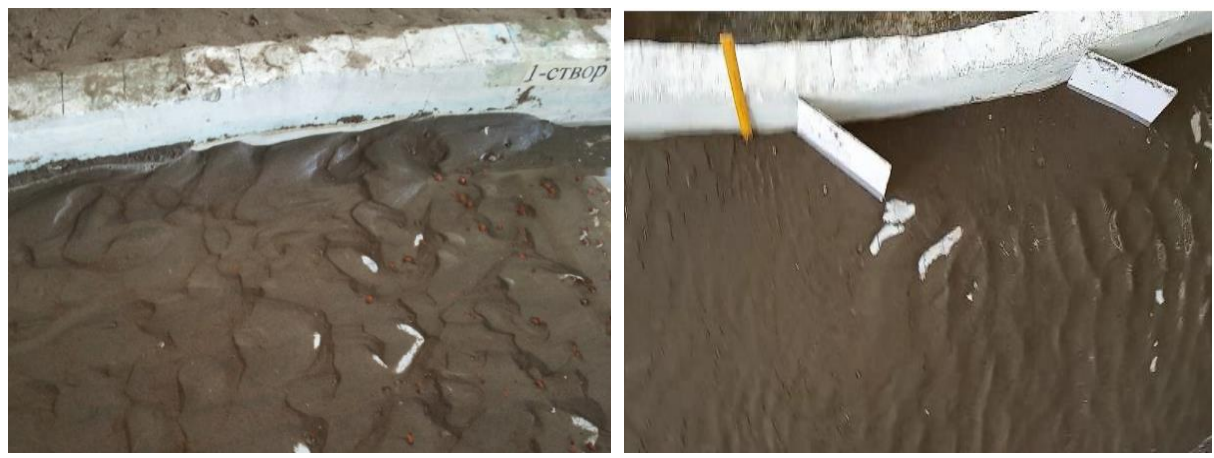

When determining the speed in the compressed section between the piles, the average household flow rate on the approach to the spur is taken $V_{\sigma}=3.5 \mathrm{~m} / \mathrm{s}$, based on the maximum water flow rate $-0.1 \%$ of availability. The building factor of the through dam is taken according to the project $\mathrm{P}=0.5$. 
According to the recommendation, the value of the optimal diameter of the rod of the model of the through dam is established as follows: first, the coefficient of local resistance is determined by the formula

$$
\xi=\beta \sqrt[3]{\left(\frac{P}{1-P}\right)^{1 / 3} K_{0} \sin \theta}=1.79 \sqrt[3]{\left(\frac{0.5}{1-0.5}\right)^{1 / 3} 1 \cdot 1}=1.27
$$

где $\beta$ is pile shape factor, for round piles, equal to 1,79 .

The average flow rate in the compressed section between the piles is calculated by the formula

$$
V_{s j}=V_{b}=\left(1+2.2 K_{C}^{0.1} \rho^{3 / 2}\right)=3.5\left(1+2.2 \cdot 1 \cdot 0.5^{3 / 2}\right)=6.24 \mathrm{~m} / \mathrm{s}
$$

Then the Reynolds number in kind will be

$$
\operatorname{Re}_{\text {Ham }}=\frac{V_{\text {сжж}} \cdot \delta}{v}=\frac{6.24 \cdot 1.6}{0.0000011}=9100000
$$

And the boundary value of the Reynolds number

$$
\operatorname{Re}_{g r}=\frac{2800}{\sqrt{1.27}}=248
$$

Then the scale factor of the distance between the spurs is set according to the formula:

$$
L_{S}=\left(\frac{\operatorname{Re}_{2 p}}{\operatorname{Re}_{\text {Ham }}}\right)^{2 / 3}=\left(\frac{2480}{9100000}\right)^{2 / 3}=\frac{1}{240}
$$

Then the gap between the piles on the model will be

$$
S_{M}=\frac{S_{H}}{240}=\frac{1600}{240}=6.7
$$

$m m$

Since the building factor in kind is taken as 0.5 , the diameter of the shell piles on the model will also be $d_{M}=6.7 \mathrm{~mm}$.

The optimal diameter of the shell piles of the weir through the threshold, which ensures the self-similarity of the flow around the flow, was also established according to the above method $-d=9 \mathrm{~m}$ with a building factor of 0.76 . An overflow threshold made of shell piles about $700 \mathrm{~m}$ long, running across the channel regulated by a through-flow dam curved in the plan, is located slightly below the ABMC head regulator's inlet channel. The threshold of the left side of the spillway for $500 \mathrm{~m}$ is located at the level of the low-water horizon of the river, the right one $-2.5 \mathrm{~m}$ below the left side, which will allow to press the flow to the inlet to the regulator during low-water periods and ensure water intake in the amount of $100 \%$ at household horizons corresponding to $99 \%$ security 


\section{Conclusions}

Based on the results of the analysis and calculations, it was established that the following conclusions and recommendations were made during the experimental modeling of channel processes of the river bed in the area of the damless water intake:

- it has been substantiated that the Amudarya sand cannot be modeled on a geometric scale since the model deposits are too small (powder) and lose the property of free-flowing bodies. In such cases, a material with a decrease in specific gravity without a decrease in diameter is used as a substitute for sand.

- since the sediment diameter cannot be reduced, the actual scale of the model remains distorted. It is indicated that the sediment diameter cannot be reduced, then in fact, the scale of the model remains distorted. Therefore, when the bottom of a river bank is made of sand that does not lend itself to geometric modeling, regardless of the change in the specific gravity of the natural material, to ensure the mobility of the sand on the model, it is necessary to distort the vertical scale;

- distortion of scales is also necessary because when using in laboratory conditions the same sand that formed the bed of the river, at any depth at a low speed, the model shows bottom resistances to the movement of the flow in comparison with nature;

- calculated the vertical and planned scales of modeling, respectively, equal to 50 and 57.

\section{References}

1. Bazarov D.R. Nauchnoye obosnovaniye novykh chislennykh metodov rascheta deformatsii rusel rek slozhennykh legkorazmyvayemymi gruntami, p. 209, Moscow, (2000)

2. Mukhamedov A.M. Osnovnyye napravleniya issledovaniy po ruslovym protsessam reki Amudarya, Doklady vsesoyuznogo soveshchaniya po vodozabornym sooruzheniyam i ruslovym protsessam, pp. 11-27, Tashkent, (1974)

3. Velikanov M.A. Morfometriya ravninnykh rek kak osnova modelirovaniya ruslovogo protsessa, Tr. II Gidrol. Syezda, T.5, pp. 268-270, Leningrad, (1960)

4. Bazarov D., Vatin N., Obidov B., and Vokhidov O. Hydrodynamic effects of the flow on the slab of the stand in the presence of cavitation. IOP Conf. Ser. Mater. Sci. Eng. 1030, 012110 (2021).

5. Bazarov D., Markova I., Norkulov B. and Vokhidov O. Hydraulic aspects of the layout of head structures during water intake from lowland rivers. IOP Conf. Ser. Mater. Sci. Eng. 1015, 012041 (2021).

6. Bazarov D., Markova I., Sultanov S. and Kattakulov F. Dynamics of the hydraulic and alluvial regime of the lower reaches of the Amudarya after the commissioning of the Takhiatash and Tuyamuyun hydrosystems. IOP Conf. Ser. Mater. Sci. Eng. 1030, 012110 (2021).

7. Bazarov D. and Vokhidov O. Extinguishing Excess Flow Energy in Spillway Structures. In book: Proceedings of EECE 2020, LNCE 150, pp. 535-545, (2021) DOI: 10.1007/978-3-030-72404-7_52

8. Bazarov D., Markova I., Norkulov B., Isabaev K., Sapaeva M. Operational efficiency of water damless intake. IOP Conf. Ser. Mater. Sci. Eng. 869(7), 072051, (2020)

9. Obidov B., Vokhidov O., Tadjieva D., Kurbanova, U., Isakov A. Hydrodynamic effects on the flow elements of the downstream devices in the presence of cavitation. IOP Conf. Ser. Mater. Sci. Eng. 1030, 012114 (2021).

10. Bazarov D., Norkulov B., Vokhidov O., Uljaev F., Ishankulov, Z. Two-dimensional flow movement in the area of protective regulatory structures. IOP Conf. Ser. Mater. Sci. Eng. 890, 012162 (2020) 
11. Krutov A., Choriev R., Norkulov B., Mavlyanova D. and Shomurodov A. Mathematical modelling of bottom deformations in the kinematic wave approximation. IOP Conf. Ser. Mater. Sci. Eng. 1030, 012147 (2021).

12. Krutov A., Norkulov B., Uljaev F., and Jamalov F. Results of a numerical study of currents in the vicinity of a damless water intake. IOP Conf. Ser. Mater. Sci. Eng. 1030, 012121 (2021).

13. Rybakov V., Jos V., Raimova I., and Kudryavtsev K. Modal analysis of frameless arches made of thin-walled steel profiles. IOP Conf. Ser. Mater. Sci. Eng. 883, (2020).

14. Matyakubov B., Begmatov I., Raimova I. and Teplova G. Factors for the efficient use of water distribution facilities. IOP Conf. Ser. Mater. Sci. Eng. 883, 012025 (2020).

15. Uralov B., Rakhmatov N., Khidirov S., Uljaev F., Raimova I. Hydraulic modes of damless water intake. IOP Conf. Ser. Mater. Sci. Eng. 1030(1), 012123 (2021)

16. Bazarov D., Markova I., Raimova I., Sultanov Sh. Water flow motion in the vehicle of main channels. IOP Conf. Ser. Mater. Sci. Eng. 883, 012025 (2020).

17. Eshev S., Latipov S., Qurbonov A., Berdiev M., Mamatov N. Non-eroding speed of water flow of channels running in cohesive soils. IOP Conf. Ser. Mater. Sci. Eng. 1030, 012131 (2021).

18. Yangiev A., Eshev S., Panjiev S., Rakhimov A. Calculation of sediment flow in channels taking into account passing and counter wind waves. IOP Conf. Ser. Mater. Sci. Eng., 883, 012036 (2020)

19. Eshev S.S., Khazratov A.N., Rahimov A.R., Latipov S.A. Influence of wind waves on the flow in flowing reservoirs. IIUM Engineering Journal, 21(2), pp. 125-132, (2020)

20. Shokirov B., Norkulov B., Nishanbaev Kh., Khurazbaev M., Nazarov B. Computer simulation of channel processes. E3S Web of Conferences, 97, 05012, (2019) 